\title{
NUREG/CR-1006
}

BNL-NUREG-51054

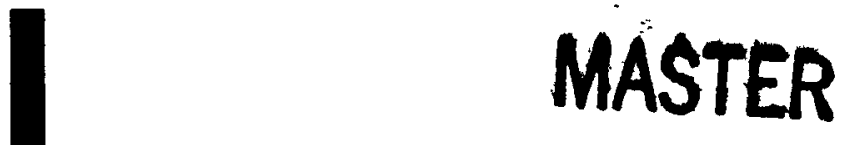

\section{PRELIMINARY DESIGN STUDY OF A LARGE SCALE GRAPHITE OXIDATION LOOP}

L.G. Epel, S. J. Majeski, D.G. SCHweitzer and T.V. Sheehan

Date Published - August 1979

\author{
HTGR SAFETY DIVISION \\ DEPARTMENT OF NUCLEAR ENERGY, BROOKHAVEN NATIONAL LABORATORY \\ UPTON, NEW YORK 11973
}

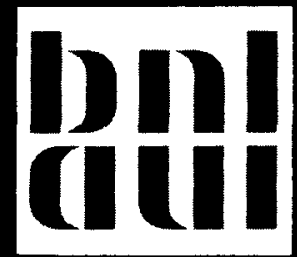

Prepared for the U.S. Nuclear Regulatory Commission

Office of Nuclear Regulatory Research

Contract No. EY-76-C-02-0016 


\section{DISCLAIMER}

This report was prepared as an account of work sponsored by an agency of the United States Government. Neither the United States Government nor any agency Thereof, nor any of their employees, makes any warranty, express or implied, or assumes any legal liability or responsibility for the accuracy, completeness, or usefulness of any information, apparatus, product, or process disclosed, or represents that its use would not infringe privately owned rights. Reference herein to any specific commercial product, process, or service by trade name, trademark, manufacturer, or otherwise does not necessarily constitute or imply its endorsement, recommendation, or favoring by the United States Government or any agency thereof. The views and opinions of authors expressed herein do not necessarily state or reflect those of the United States Government or any agency thereof. 


\section{DISCLAIMER}

Portions of this document may be illegible in electronic image products. Images are produced from the best available original document. 


\title{
PRELIMINARY DESIGN STUDY OF A LARGE SCALE GRAPHITE OXIDATION LOOP
}

\author{
L.G. Epel, S. J. Majeski, D.G. Schweitzer and T.V. Sheehan
}

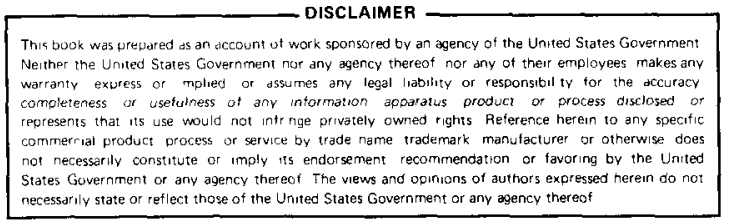

Manuscript Completed - July 1979

Date Published - August 1979

\author{
HTGR SAFETY DIVISION \\ DEPARTMENT OF NUCLEAR ENERGY \\ BROOKHAVEN NATIONAL LABORATORY \\ ASSOCIATED UNIVERSITIES, INC. \\ UPTON, NEW YORK 11973
}

PREPARED FOR THE UNITED STATES NUCLEAR REGULATORY COMMISSION DIVISION OF REACTOR SAFETY RESEARCH, OFFICE OF NUCLEAR REGULATORY RESEARCH UNDER CONTRACT N0. EY-76-C-02-0016

NRC FIN NO. A-3016 
VOTIC'E

This report was prepared as an account of work sponsored by an agency of the United States Government Neither the United States Government nor any agency thereof, or any of their employees, makes any warranty expressed or implied, or assumes any legal liability or responsibility for any third party's use, or the results of such use, of any information, apparatus, product or process disclosed in this report, or represents that its use by such third party would not infringe privately owned rights

The vews expressed in this report are not necessaril those of the US Nuclear Regulatory Commission

Avallable from

Natıonal Technical Information Service

Springfield, Vırgınıa 22161 
Page

Abstract

vi

List of Tables

$\mathrm{v}$

List of Figures $\quad v$

1 Introduction 1

2 Nominal Design of a Graphite Oxidation Loop 1

2.1 International Survey of High Temperature- 2

High-Pressure Loops

2.2 System Description of Nominal Design 2

2.3 Test Section Design 4

2.4 Recuperators and Dump Heat Exchanger 4

2.4.1 Recuperator 5

2.4.2 Air Cooler 5

2.5 Helium Circulator and Motor 6

2.6 Electric Heaters

2.7 Impurities Control

2.7.1 Water Addition 7

2.7.2 Carbon Monoxide Removal 8

2.7.3 Hydrogen Removal 8

2.7.4 Impurities Removal With Activated Charcoal 8

2.8 Valves and Piping 10

2.9 Analytical, Recording, and Control System 10

2.9.1 Analytical Instruments 10

2.9.2 Recording Devices 11

2.9.3 Control System 11

3 Calculational Basis for the Nominal Design 12

3.1 Chemistry of Graphite Oxidation $\quad 12$

3.2 Heat Transfer and Fluid Dynamics Considerations 15

3.2.1 Recuperator Size 15

3.2.2 Air Cooler Size 16

3.2.3 Pressure Losses $\quad 16$

4 Loop Operation $\quad 17$

4.1 Startup and Shutdown $\quad 17$

4.2 Off-Normal Conditions 18

4.2.1 Loss of Helium Flow 18

4.2.2 Rapid Depressurization 18 


\section{TABLE OF CONTENTS - Cont' $d$.}

5 Alternative Designs

5.1 Low Pressure Loop

5. 2 Chamber Design

6 Capital Cost Estimates

6.1 Nominal Design

6.2 Low Pressure Loop

6.3 Chamber Design

7 Conclusions and Recommendations

References 


\section{LIST OF TABLES}

Page

Table 2.1 Current High Pressure-High Temperature Loops for HTGR Safety Research

Table 2.2 Average Rupture Life Strength at $1800 \mathrm{~F} \quad 4$

Table 2.3 Effect of Fraction Processed on Makeup Rate 10

$\begin{array}{lll}\text { Table 5.1 Comparison of System Parameters } & 20\end{array}$

Table 6.1 Capital Cost Estimate for Three Designs 22

LIST OF FIGURES

Figure 2.1 Process Flow Diagram - Nominal Design 25

Figure 2.2 Preliminary Arrangement of Graphite Oxidation Loop 26

$\begin{array}{lll}\text { Figure 2.3 Test Section (Nominal Design) } & 27\end{array}$

Figure 2.4 Test Section (With Therma1 Barrier) . 27

$\begin{array}{lll}\text { Figure 2.5 Recuperator } & 28\end{array}$

Figure 5.1 Chamber Design Assembly 29 


\section{ABSTRACT}

A preliminary design study of a large scale graphite oxidation loop was performed in order to assess feasibility and to estimate capital costs. The nominal design operates at 50 atmospheres helium and $1800 \mathrm{~F}$ with a graphite specimen 30 inches long and 10 inches in diameter. It was determined that a simple single walled design was not practical at this time because of a lack of commercially available thick walled high temperature alloys.

Two alternative concepts, at reduced operating pressure, were investigated. Both were found to be readily fabricable to operate at $1800 \mathrm{~F}$ and capital cost estimates for these are included.

A design concept, which is outside the scope of this study, was briefly considered. The full design pressure, temperature and dimensions of the nominal design could possibly be accommodated in a design in which the pressure boundaries of the loop are maintained at lower temperatures through use of thermal barriers and/or double walled sections. This would greatly complicate the mechanical design of the test section, the heat exchangers, and the piping, however. 


\section{INTRODUCTION}

Many of the internals of the High Temperature Gas Cooled Reactor (HTGR) are fabricated of graphite because of the excellent high temperature properties of this material. The nominal design of the large HTGR calls for a nuclear grade graphite (H451) for core components, type ATJ or possibly type 2020 for the core support posts, and type PGX for the core support blocks. Other types of graphite have been used in gas cooled reactors in the United States and abroad and there are yet other candidate graphites being considered for future systems. Each type has its own peculiar characteristics within the graphite family, notably its resistance to corrosion in impure helium.

The study of graphite for nuclear application is over 35 years old and the literature abounds with theoretical and experimental information. Unfortunate$1 y$, there is a lack of well understood theory that can be used to predict the behavior of a new type of graphite with sufficient confidence for nuclear power plant application. As a result, testing of critical components is essential for safety reasons. Such tests are usually conducted in loops that simulate some parameters of the operating system but do not match others; the discrepancy is adjusted for by suitable theoretical arguments. Testing large samples at the high temperatures, high pressures, large flow rates and in the radiation fields representative of prototypic reactor conditions would be prohibitively expensive, especially for long term exposures. Thus, in most graphite test loops compromises with reality are made, usually by sacrificing sample size.

The United States does not have any large scale graphite oxidation facility to test graphite specimens for HTGR application. If a steam generating HTGR, such as Fort St. Vrain, is to operate at rated conditions, safety related questions regarding graphite corrosion in helium with small amounts of water vapor, hydrogen, carbon monoxide, carbon dioxide, methane, etc. arise. A preliminary design study was performed by the HTGR Safety Division at Brookhaven National Laboratory for the Reactor Safety Research Division of the U. S. Nuclear Regulatory Commission to determine the feasibility of constucting a large scale graphite oxidation loop and to estimate the cost of constructing such a facility. This report summarizes the results of that study.

\section{NOMINAL DESIGN OF A GRAPHITE OXIDATION LOOP}

To begin a preliminary design in order to assess feasibility and to scope capital costs of components for a large scale graphite oxidation loop, several basic parameters must be set somewhat arbitrarily. The test section operating pressure and temperature for the nominal design was set at the maximum prototypic reactor conditions $(735$ psia and $1800 \mathrm{~F})$. To limit the decrease in water vapor concentration across the test section, containing a graphite sample chosen as 30 inches long and 10 inches in diameter, to 5 percent necessitated a helium flow rate of $922 \mathrm{cfm}$ (see Section 3.1). These parameters determine the nominal design of the loop. Besides the nominal design, 2 alternative approaches were studied. The first is simply a low pressure version ( 50 psia) of the nominal 
design with an appropriately different helium flow rate. The second alternative also maintains the high temperature of the nominal design but accomplishes this by reverting to a pressure chamber design, rather than a circulating system, thereby compromising the fluid dynamics of the nominal design. These two designs are discussed in Section 5.

\subsection{International Survey of High Temperature-High Pressure Loops}

In support of HTGR technology, a number of loops have been built and operated in Europe and in Japan. Currently, General Atomic Company is completing construction of a small high temperature-high pressure loop to study graphite oxidation. Except for the OSIRIS loop at Saclay and the OGL-1 in Japan, all have been out of pile systems. Of the 17 loops reviewed, 6 combine a reasonably high helium flow rate with prototypic temperature and pressure.

Table 2.1 summarizes the salient features of all test loops whose characteristics were outlined in the references shown. For the sake of comparison with this table, the nominal design of the large scale graphite oxidation loop described in this study calls for a test section temperature of $1000 \mathrm{C}$, a system pressure of 50 bar, a helium flow rate of $850 \mathrm{grams} / \mathrm{second}$, a test section size 30 centimeters times 76 centimeters, and a required electrical power input of 120 kilowatts.

\subsection{System Description of Nominal Design}

A schematic of the nominal design is given in Figure 2.1. Helium from the test gection is led to the tube side of the first recuperator where its temperature is decreased 25 percent of the way to $1050 \mathrm{~F}$. In the next 3 recuperators the remaining 75 percent temperature drop is experienced. The helium then passes through an air blast heat dump which cools it further to $1000 \mathrm{~F}$. The helium is now cool enough to enter the circulator and then proceed to the shell sides of the recuperators countercurrent to the tube side helium. The final $50 \mathrm{~F}$ is added to the helium emerging from the high temperature recuperator by the electric heaters and the helium is then led back into the test section. A variation of this flow path involves leading $1000 \mathrm{~F}$ helium to the shell side of the test section before routing it to the recuperators (see dotted lines on Figure 2.1). This variation is discussed in connection with test section design in Section 2.3.

Not shown in the schematic are the lines that lead a small bleed stream of $1000 \mathrm{~F}$ helium from the main circuit to an analytic instrument bank and an impurities control system. The instruments and purification/injection system operate at ambient conditions and thus a booster pump is also required to lead this side stream back into the main circuit. Figure 2.2 depicts the arrangement of the major components of the 1oop. A detailed thermal stress analysis was beyond the scope of this study but the arrangement is conceived to accommodate the anticipated stresses. 
Table 2.1

Current High Pressure-High Temperature Loops for HTGR Safety Research

\begin{tabular}{|c|c|c|c|c|c|c|c|c|}
\hline Name & Location & $\begin{array}{l}\text { Max. } \\
\text { Temp. } \\
{ }^{\circ} \mathrm{C} \\
\end{array}$ & $\begin{array}{c}\text { Pressure } \\
\text { Bar } \\
\end{array}$ & $\begin{array}{l}\text { Max. } \\
\text { Flow Rate } \\
\mathrm{gm} / \mathrm{sec} \\
\end{array}$ & $\begin{array}{c}\text { Size of } \\
\text { Test Section } \\
\text { cm Dia } \times \mathrm{cm} \mathrm{Ht} \\
\end{array}$ & $\begin{array}{c}\text { Elec. Heat } \\
\text { Input } \\
\mathrm{kW} \\
\end{array}$ & Comment & Ref. \\
\hline Carmen 2 & Saclay, France & 450 & 45 & 28,000 & $125 \times--$ & 1000 & $\begin{array}{l}4 \text { blowers at } \\
750 \mathrm{~kW} \mathrm{each}\end{array}$ & 3 \\
\hline Saclay 1 & Saclay, France & 1200 & 60 & 2 & $1.2 \times 18.0$ & -- & & 1 \\
\hline Saclay 2 & Saclay, France & 1200 & 60 & 6 & $2.4 \times 80.0$ & -- & & 1 \\
\hline Spitfire & Saclay, France & 650 & 60 & 37 & $6.0 \times 49.5$ & -- & $\begin{array}{l}\text { In-pile (OSIRIS) } \\
\text { loop }\end{array}$ & 1 \\
\hline SMOC & Julich, Germany & 900 & 80 & 695 & $5.0 \times 600.0$ & 1000 & $\begin{array}{l}\text { Flow rate based } \\
\text { on } \mathrm{N}_{\mathrm{Re}}=3.5 \times 10^{5}\end{array}$ & 1 \\
\hline $\begin{array}{l}\text { Austrian } \\
\text { Test Fac. }\end{array}$ & $\begin{array}{l}\text { Seibersdorf, } \\
\text { Austria }\end{array}$ & 1000 & 100 & 556 & $100 \times 700$ & 1000 & & 2 \\
\hline SGL & Jaeri, Japan & 1100 & 2 & 10 & $2.5 \times--$ & 100 & & 2,4 \\
\hline HTGL & Jaeri, Japan & 1000 & 41 & 100 & $7.5 \times--$ & 270 & & 2,4 \\
\hline OGL -00 & Jaeri, Japan & 400 & 49 & 500 & $10 \times--$ & 100 & & 4 \\
\hline OGL-1 & Jaeri, Japan & 1000 & 34 & 100 & $4.9 \times--$ & 150 & $\begin{array}{l}\text { In-pile (JMTR) } \\
\text { loop }\end{array}$ & 2,4 \\
\hline $\begin{array}{l}\text { Multi-Pur- } \\
\text { pose loop }\end{array}$ & MHI, Japan & 1000 & 49 & 10 & 40.6 and 10.0 & 38 & & 4 \\
\hline HTL-10 & IHI, Japan & 1000 & 14 & 5.6 & $3.4 \times--$ & 95 & & 4 \\
\hline HTL -40 & IHI, Japan & 1000 & 40 & 111 & $6.1 \times--$ & 230 & & 4 \\
\hline HRL & Hitachi, Japan & 1000 & 21 & 10 & $3.4 \times--$ & 52 & & 4 \\
\hline $\mathrm{KHI}-\mathrm{sma11}$ & Kawasaki, Japan & 1000 & 40 & 3.3 & $7.6 \times--$ & 18 & & 4 \\
\hline KHI-medium & Kawa saki, Japan & 1000 & 40 & 400 & $31.9 \times \rightarrow$ & 1500 & $\begin{array}{l}\text { Construction } \\
\text { started in } 1978\end{array}$ & 4 \\
\hline HPTL & San Diego, U.S. & 1000 & 50 & 2 & $7.6 \times 15.2$ & -- & $\begin{array}{l}\text { Presently being } \\
\text { completed }\end{array}$ & 5 \\
\hline
\end{tabular}

1. 0. P. Chawla and A. W. Barse11, An Evaluation of Integral Experiments and Potential Test Facilities for Future Fission Product Safety Research, GA-A 14205, May 1977.

2. Gas Cooled Reactors With Emphasis on Advanced Systems, Proceedings of a Symposium at Julich in October 1975, ISBN 92-0-050076-5, March 1976.

3. Gas Cooled Reactors: HTGR and GCFBR, Proceedings of a Topical Meeting at Gatlinburg in May 1974, CONF-740501

4. Proceedings of the Japan-U.S. Seminar in HTGR Safety Technology at BNL in September 1977, BNL-NUREG-50689, Vol. II.

5. Personal communication with R. D. Burnette, July 1978. 


\subsection{Test Section Design}

The high temperature and pressure to which the test section will be subjected requires heavy walled sections of high temperature alloy. A review of available materials indicates 2 candidate alloys - Inconel 617 and Hastelloy X. In the large loop currently being built by Kawasaki Heavy Industries for the Japan Atomic Energy Research Institute (JAERI), the preference seems to be for Hastelloy $\mathrm{X}$. As Table 2.2 shows, however, the high temperature rupture life strength of Inconel 617 is somewhat superior to that of Hastelloy X. For that reason, and because both alloys are probably equally available from commercial suppliers, Inconel 617 is preferred for this design.

Table 2.2

Average Rupture Life Strength at $1800 \cdot \mathrm{F}$, Kpsi (MPa)

100 hours 1,000 hours 10,000 hours 100,000 hours*

$\begin{array}{cccccc}\text { Hastelloy X } & 4.2(29) & 2.4(17) & 1.4(9.7) & .95(6.6) \\ \text { Incone1 617 } & 5.6(39) & 3.75(26) & 2.67(18) & 1.8(12)\end{array}$

*Extrapolated

Figure 2.3 shows the nominal design test section required to accommodate a 30 inch long by 10 inch diameter graphite sample based on the rupture strengths shown in Table 2.2 for 100,000 hours. The walls are 3 inches thick and the total weight of this component is estimated to be about 4 tons.

An alternative design, which eliminates the need for heavy sections of high temperature alloy, is shown in Figure 2.4. This concept involves high pressure helium on both sides of the "thermal shield." The helium on the "shell side" of the test section is at 1000 F and insulates the "shell" from the test section temperature. The thermal shield is exposed to $1800 \mathrm{~F}$ helium but need not sustain a high pressure difference. The shell is the pressure barrier but operates at $1000 \mathrm{~F}$, a temperature regime in which ordinary steels may be used. This design leads to a number of complications which may not be compensated for by the potential cost savings associated with avoiding heavy walled Inconel sections. Further, although a similar method may be employed in the recuperators in principle, in practice, this is judged to be impractical. Since the costs of heavy walled sections of high temperature alloys is essentially unavoidable for the recuperators, the amount to be saved by using the alternative test section design becomes, by contrast, questionable. The nominal design is therefore based on the test section illustrated in Figure 2.3.

\subsection{Recuperators and Dump Heat Exchanger}

The heat exchangers required for the nominal design are the recuperators, whose purpose is to reduce loop energy requirements, and the helium cooler, which lowers the temperature of the helium to the $1000 \mathrm{~F}$ required at the circulator inlet. These devices are described in general terms in the 
succeeding 2 sections; process calculations are given in Section 3.2 .

\subsubsection{Recuperator}

Four sections (or stages) of recuperator were chosen in an attempt to contain the extremely high temperatures, requiring special high temperature alloys, to only one section. The total temperature change in the recuperator was taken as $750 \mathrm{~F}$, somewhat arbitrarily, with the remaining $50 \mathrm{~F}$ decrease of the helium to be taken by the air blast cooler. Four sections, carrying the required duty, result in reasonable tube lengths and shell diameters for reasonable helium velocities and affordable pressure drops. Optimization of the many heat exchanger variables, including capital cost considerations, during the formal process design of the recuperator may point to a change in the number of stages and the distribution of duties. For purposes of this study, however, 4 equal sections appear to be an excellent choice.

As shown in Section 3.2.1, when the tube diameter and helium velocity are chosen the other design parameters axe determined for a given mass flow rate and duty. The result of choosing a tube diameter of $1 / 2$ inch and a flow velocity of $100 \mathrm{feet} / \mathrm{second}$ is that a bundle of 170 tubes, 68 feet 1 ong, will be required. If these were placed in $4 \mathrm{U}$-tube bundles, the bundles would be about 8 feet long. When the tubes are placed on $3 / 4$ inch centers the diameter of the U-tube bundle is about 16 inches. Alternatively, the required heat transfer surface could be provided by $3 \mathrm{U}$-tube bundles, each 12 feet long and having the same overall diameter. The former option was chosen in this study and is illustrated in Figure 2.5.

The $50 \mathrm{~F}$ temperature differential between tube and shell sides is by no means an optimal design. It is based on engineering judgement that this will result in manageable thermal expansion problems. The recuperators can be 2 pass units with U-tubes or single pass U-tube units. Either type of construction minimizes thermal expansion problems and is quite common in industry.

\subsubsection{Air Cooler}

The design of the air cooler is based on an overall heat transfer coefficient of $15 \mathrm{Btu} / \mathrm{hr}-\mathrm{ft}^{2} \mathrm{~F}$. Most of the resistance to heat flow in the air cooler will be on the air side and the value chosen is consistent with past experience with similar air cooled devices.

The air is assumed to enter the heat exchanger at $70 \mathrm{~F}$ and flows countercurrent over the helium filled tubes, exiting at $800 \mathrm{~F}$. This latter temperature is arbitrary but consistent with air blast heat dumps ordinarily encountered in engineering practice.

In sizing the dump heat exchanger, $11 / 4$ inch diameter tubes were used and a tube side helium velocity of $50 \mathrm{feet} / \mathrm{second}$ was assumed. The resulting design consists of a 21 tube bundle which is 8 feet long. Placing these tubes on 2 inch centers yields an overall bundle diameter of approximately 11 inches, a design which is easily accommodated. 


\subsection{Helium Circulator and Motor}

A critical (and the most expensive) component in the large scale graphite oxidation loop is the helium circulator and its motor and power supply. The Department of Nuclear Energy at Brookhaven National Laboratory has had experience in acquiring, installing and operating gas circulators at high temperatures and pressures for previous experimental loops but at lower rates of flow than called for in this design. A number of manufacturers have been utilized in the past with mixed results. The Chemonuclear Loop, which operated at BNL during 1969, achieved good results with a gas circulator designed and manufactured by Mechanical Technology Incorporated of Latham, New York. This company is still active, and indeed is supplying circulators to the DOE for other gas cooled reactor test facilities. Accordingly, MTI was contacted and was asked to prepare a proposal for a helium circulator with the following preliminary specifications:

$\begin{array}{lr}\text { Inlet Pressure } & 735 \text { psia } \\ \text { Discharge Pressure } & 760 \text { psia } \\ \text { Inlet Temperature } & 1000 \mathrm{~F} \\ \text { Flow (at Inlet Conditions) } & 600 \mathrm{cfm}\end{array}$

Mechanical Technology Incorporated has tentatively proposed a one stage centrifugal compressor, operating on gas bearings hermetically housed in a stainless steel vessel designed and fabricated to ASME Code VIII and driven by a helium cooled $140 \mathrm{hp}, 24,000 \mathrm{rpm}$ induction motor.l

The preparation of the design, layout, detailed drawings and an engineering report for the helium circulator would take approximately 6 months, according to MTI and would cost about $\$ 130,000$ on a cost plus fixed fee basis. A budgetary estimate for the fabrication, assembly, testing and delivery of the final design is $\$ 660,000$. The circulator and motor would account for rough1y $\$ 550,000$ of this amount, with the remainder accounting for the power supply.

Discussions with engineers at MTI indicate that the cost of the circulator will not be strongly influenced by changing the inlet temperature of the helium, provided the same compressor design concept is maintained. 2 This is because a critical cost parameter is the size of the motor; it is the motor dimensions that will determine the size of the pressure vessel required to house the circulator-motor. The size of the motor depends primarily on the power requirements and this, in turn, depends on the helium mass flow rate and the desired head rise through the circulator. Since these latter two variables are necessarily fixed by considerations of graphite chemistry and the mechanical design restrictions inherent in the loop design, the cost of the circulator is essentially predetermined as well. It has been estimated by MTI that lowering the circulator inlet temperature to $200 \mathrm{~F}$ would result in less than a 10 percent cost reduction for the circulator. These considerations were taken into account when alternate designs for the graphite oxidation loop (i.e. lower pressure and/or lower circulator inlet temperature) were contemplated. 


\subsection{Electric Heaters}

The commercial availability of electric heaters that will boost the helium temperature from $1750 \mathrm{~F}$ to $1800 \mathrm{~F}$ was determined to be an important factor in the feasibility of the large oxidation loop. Roughly 120 kilowatts must be supplied to the helium going to the test section and two schemes appear practical.

The first alternative resembles either a pancake coil or a long, straight calrod type element. The other kind consists of clam shells with thin coils of wire on the inside of the clam shell. Such devices, although they are more fragile than the former kind, are readily available commercially and were therefore chosen for purposes of estimating costs in this study. They would be mounted on the inside of the piping leading to the test section so that the helium would be in direct contact with the heating element wire. This will necessitate careful design of the electrical connections to the heaters through the pipe walls. Attention to this detail was not spent for the purposes of this study.

\subsection{Impurities Control}

The oxidation of PGX graphite at $1800 \mathrm{~F}$ results in the generation of carbon monoxide and hydrogen and the depletion of water vapor according to the "watergas reaction"

$$
\mathrm{C}+\mathrm{H}_{2} \mathrm{O}=\mathrm{CO}+\mathrm{H}_{2}
$$

If the loop is to operate under long term, steady conditions, facilities ifor replenishing the water and for removing carbon monoxide and hydrogen must be pro-. vided. Some alternative techniques for accomplishing this are considered in this section.

\subsubsection{Water Addition}

A number of methods for supplying water to the experimental system are available. First it is necessary to estimate the required rate of water makeup. For this purpose the nominal design conditions and the ehemistry assumptions in Section 3.1 are used. The rate of reaction with water for a 10 inch diameter by 30 inch long specimen is shown to be (see Section 3.1):

$$
\begin{aligned}
\sqrt{\mathrm{K}_{\mathrm{V}} \mathrm{Z}} \mathrm{A}_{\mathrm{S}} \mathrm{C}_{\mathrm{O}} & =\sqrt{2.12 \times 10^{7} \times 6.19 \times 10^{-3}} 7.64 \mathrm{C}_{\mathrm{O}} \\
& =2766 \mathrm{C}_{\mathrm{O}} 1 \mathrm{~b} / \mathrm{hr}
\end{aligned}
$$

where $C_{o}$ is the steam concentration at the surface of the graphite. The OXIDE -3 code $^{3}$ predicts that for a water ingress rate of 0.09 pounds/hour, which results in a total oxidant level in the HTGR of 10 parts/million*, the partial pressure of steam will be $2.4 \times 10^{-5}$ atmospheres. Using this value in

*This is the technical specification limit for total oxidants in the primary system. 
Equation (2-2) results in a required water makeup rate of $7.24 \times 10^{-4}$ pounds/hour. This rather small amount $\left(9 \times 10^{-5}\right.$ gallons/hour $)$ is readily injected by either of 2 methods used in existing test loops at Brookhaven.

One method utilizes the water vapor which is in equilibrium with a mixture of 10 percent anhydrous oxalic acid and 90 percent oxalic acid dihydrate. The water of hydration is driven off easily with an increase in the mixture temperature. Adoption of this technique, which has proven successful in the Materials Test Loop at BNL, would require about 25 pounds of oxalic acid per year.

The other method is simply to bubble helium through a vessel which contains water and allow some water vapor to become entrained in the helium side stream, which then returns to the main stream. Control of the water vapor level is maintained by valving the helium side stream with flow controllers and solenoid valves. A similar method has been used with the Helium Impurities Loop at BNL and resulted in good control of the water vapor level.

\subsubsection{Carbon Monoxide Removal}

The selective removal of carbon monoxide can be easily accomplished over a wide range of temperatures by passing a side stream of helium through a calcium bed according to the reaction

$$
\mathrm{Ca}+\mathrm{CO}=\mathrm{CaO}+\mathrm{C}
$$

The standard free energy change for this reaction at room temperature is -111.4 kilocalories and decreases in magnitude with increase in temperature. At $1000 \mathrm{~F}$ the standard free energy change is -88.5 kilocalories, still large enough to effectively remove all of the carbon monoxide. Since each mole of $\mathrm{H}_{2} \mathrm{O}$ produces one mole of $\mathrm{CO}$, which, in turn, requires one mole of calcium for its removal, the annual requirement for fresh calcium under the assumptions used in Section 2.7 .1 will be about 14 pounds.

\subsubsection{Hydrogen Removal}

Hydrogen which is generated during the water-gas reaction can be removed by passing the hydrogen contaminated helium over a mixture of zirconium and titanium chips. These metals will form hydrides readily at temperatures of about 500-600 F. However, any water vapor present in the helium will react with these chips and generate fresh hydrogen; therefore, the tank containing the Ti-Zr must be preceded by a desiccant such as "Drierite" or "Anhydrone." This technique was used for a short time in the BNL Materials Test Loop.

\subsubsection{Impurities Removal With Activated Charcoal}

Rather than removing the oxidation products selectively, an alternative procedure is to remove all of the helium impurities in a side stream and replenish the impurities to bring them back up to the desired concentrations. Activated charcoal or molecular sieves are effective for this purpose, especially if they are maintained at liquid nitrogen temperatures. Such "traps" can be 
essentially 100 percent effective in removing impurities if the design of the tanks containing these materials provides a suitable residence time.

It is instructive to consider the effect of varying the fraction of the helium flow that is processed to remove impurities. If the concentration of each of the 3 contaminants is to be constant with time, a material balance for each yields

$$
\begin{aligned}
& \frac{\mathrm{VdC}_{\mathrm{H}_{2} \mathrm{O}}}{\mathrm{dt}}=\mathrm{S}_{\mathrm{H}_{2} \mathrm{O}}-\mathrm{f} Q \mathrm{C}_{\mathrm{H}_{2} \mathrm{O}}-\mathrm{R}=0 \\
& \frac{\mathrm{VdC}{ }_{\mathrm{CO}}}{\mathrm{dt}}=S_{\mathrm{CO}}-\mathrm{f} Q \mathrm{C}_{\mathrm{CO}}+\frac{14}{9} \mathrm{R}=0 \\
& \frac{\mathrm{VdC}_{\mathrm{H}_{2}}}{\mathrm{dt}}=\mathrm{S}_{\mathrm{H}_{2}}-\mathrm{f} Q \mathrm{C}_{\mathrm{H}_{2}}+\frac{1}{9} \mathrm{R}=0
\end{aligned}
$$

where

$$
\begin{aligned}
& \left.\mathrm{V}=\text { total volume of helium in loop ( } \mathrm{ft}^{3}\right) \\
& \mathrm{S}=\text { source term due to replinishment }(1 \mathrm{~b} / \mathrm{hr}) \\
& \mathrm{f}=\text { fraction of total helium flow processed } \\
& \mathrm{Q}=\text { total helium volumetric flow } \mathrm{rate}\left(\mathrm{ft}^{3} / \mathrm{hr}\right) \\
& \mathrm{C}=\text { concentration of impurity }\left(1 \mathrm{~b} / \mathrm{ft}^{3}\right) \\
& \mathrm{R}=\text { rate of water reaction with graphite }(1 \mathrm{~b} / \mathrm{hr})
\end{aligned}
$$

The coefficients in the last term of Equations (2-4b) and (2-4c) express the fact that for each mole of water vapor consumed one mole each of carbon monoxide and hydrogen is generated and reflects the differences in their molecular weights. For the nominal design conditions $R=7.24 \times 10^{-4} 1 \mathrm{~b} / \mathrm{hr}$ ( 2.7.1) and the volumetric flow rate in the test section is $55,300 \mathrm{ft}^{3} / \mathrm{hr}$ (see Section 3.1). The OXIDE-3 code predicts the following concentrations at equilibrium with a water ingress rate of $0.09 \mathrm{lb} / \mathrm{hr}$ :

$$
\begin{aligned}
& \mathrm{H}_{2} \mathrm{O}: 2.59 \times 10^{-7} 1 \mathrm{~b} / \mathrm{ft}^{3} \\
& \mathrm{CO}: 7.70 \times 10^{-6} 1 \mathrm{~b} / \mathrm{ft}^{3} \\
& \mathrm{H}_{2} \text { : } 5.51 \times 10^{-7} \mathrm{lb} / \mathrm{ft}^{3}
\end{aligned}
$$

Thus, Equations (2-4) can be rewritten as

$$
\begin{aligned}
\mathrm{S}_{\mathrm{H}_{2} \mathrm{O}} & =.0143 \mathrm{f}+7.24 \times 10^{-4} \\
\mathrm{~S}_{\mathrm{CO}} & =.426 \mathrm{f}-1.12 \times 10^{-3} \\
\mathrm{~S}_{\mathrm{H}_{2}} & =.0305 \mathrm{f}-8.05 \times 10^{-5}
\end{aligned}
$$

This set of equations gives the rate of water vapor, carbon monoxide, and hydrogen makeup as a function of fraction of total helium circulation that is processed, assuming that the activated charcoal removes all of the impurities. Since the makeup for $\mathrm{CO}$ and $\mathrm{H}_{2}$ cannot be smaller than zero, Equations (2-5) 
defines a minimum processing fraction to remove these 2 contaminants. Table 2.3 summarizes these results.

Table 2.3

Effect of Fraction Processed on Makeup Rate

Fraction Processed

0.00264

0.0050

0.01

0.10

1.00

\begin{tabular}{|c|c|c|}
\hline $\mathrm{H}_{2} \mathrm{O}$ & $\mathrm{CO}$ & $\mathrm{H}_{2}$ \\
\hline $7.6 \times 10^{-4}$ & 0.0 & 0.0 \\
\hline $7.9 \times 10^{-4}$ & $1.0 \times 10^{-3}$ & $7.3 \times 10^{-5}$ \\
\hline $8.6 \times 10^{-4}$ & $3.2 \times 10^{-3}$ & $2.3 \times 10^{-4}$ \\
\hline $2.2 \times 10^{-3}$ & $4.2 \times 10^{-2}$ & $3.0 \times 10^{-3}$ \\
\hline $1.5 \times 10^{-2}$ & $4.3 \times 10^{-1}$ & $3.0 \times 10^{-2}$ \\
\hline
\end{tabular}

\subsection{Valves and Piping}

Because materials selection is limited to a few expensive, high temperature alloys, valves are deliberately omitted from the main stream high temperature regions. Impurities control and gas sampling, whenever necessary, can be accomplished through smaller branch connections in the cooler regions. In this manner conventional, intermediate pressure/temperature stainless steel valves can be used. Pipe materials, by necessity, when located in high temperature regions will be constructed of special thick walled Inconel 617 alloy.

A possible alternate might be jacketed piping. In principle, it would be a single tube in single shell conduit with high temperature gas on the tube side and lower temperature gas on the shell side with both gas pressures equal. This would, however, require either bellows or slip joints to compensate for thermal expansion differences.

\subsection{Analytical, Recording, and Control System}

The graphite oxidation loop is designed to be essentially automatic and self regulating during long term operation. For this purpose it is necessary to supply analytic instruments that monitor temperatures, pressures, flow rates, and impurity levels as well as recording devices that will produce permanent records of these parameters. Further, controls and regulators must be included so that the desired levels of all the parameters can be maintained automatically while the loop is unattended. These devices are briefly described in this section.

\subsubsection{Analytical Instruments}

Commercially available electronic sensors that monitor pressure and flow rates in gas process equipment have been used routinely in the HTGR Safety Division loops at BNL and appear suitable for the large scale graphite oxidation loop. Similarly, standard types of thermocouples, properly shielded and insta1led, will provide accurate temperature monitoring. It is usually convenient 
to include instruments that give quick visual assurances of key variables in a flowing gas system and bourdon type pressure gauges and rotameters will be included for this purpose.

The impurities of interest in this system are carbon dioxide, carbon monoxide, hydrogen, water vapor, and possibly methane and oxygen. Non-dispersive infrared absorption detectors have been found to be reliable for $\mathrm{CO}, \mathrm{CO}_{2}$, $\mathrm{CH}_{4}$, and water vapor and should be considered for this application. The dewpoint instruments often used for water vapor determination, although accurate, require operator attention and do not give continuous readings as the NDIR instruments do. Experience with aluminum oxide capacitance sensors for water vapor detection has been less than satisfactory in terms of their accuracy.

The monatomic gases cannot be measured by infrared techniques. Oxygen can be measured using gas chromatography in an automatic, repetitive fashion using helium as the carrier gas. Hydrogen can also be measured with a gas chromatograph but a different carrier gas, such as argon, must be used. Peak area integrators that make base line corrections, etc. are available from a number of manufacturers.

An alternative method of analyzing for impurities consists of utilizing the mass spectrometer recently purchased from Nuclide Corporation. The mass spectrometer is capable of measuring nuclides with weights from below 1 to over 500 . Some additional software, together with a few logic circuits and solenoid valves, would make automatic control of impurity levels in the loop possible.

\subsubsection{Recording Devices}

Standard multipoint and pen recorders and digital data acquisition systems have the sophistication and flexibility needed for recording the data and process variables as they are sensed by the analytical system. Modern data acquisition systems have the facility to manipulate data and make decisions based on prescribed limits and/or store data in various forms such as on magnetic tape, punch tape, in solid state memories, etc. Numerous manufacturers have a wide variety of recording systems available that would be suitable for the test loop.

\subsubsection{Control System}

Much of the process control instrumentation is integral with the recording devices. For example, multipoint recorders typically have high and low level alarm circuits built into them. These have been utilized in the Materials Test Loop to actuate solenoid valves that temporarily open lines to source cylinders or other lines leading to stripping tanks.

Control of temperature is routinely achieved with standard type temperature controllers; helium pressure is maintained by a bank of supply cylinders and suitable reducing valves; flow rates are varied by valving and where necessary by automatic flow controllers. All of these devices, as well as the requisite pressure relief valves, power limiters, and motor trippers, which are included 
to protect the system from overheating or overpressurizing, are standard commercially available items.

3. CALCULATIONAL BASIS FOR THE NOMINAL DESIGN

The helium flow rate for a given specimen size and for stipulated test conditions is determined by the kinetics of graphite oxidation in an impure environment. This in turn determines the required duties of heat exchangers, capacity of circulators, sizes of piping and valves and power requirements of the loop. The chemistry of graphite oxidation and the basic process calculations used in this study are reviewed in this section.

\subsection{Chemistry of Graphite Oxidation}

The parameters of the graphite oxidation loop, such as flow rate, pressure, temperature, etc. are determined by considerations of actual reactor conditions combined with a model of the phenomenon being investigated in the loop. In order to appreciate the choice of design values imposed on the system in this study it is therefore necessary to understand the model of graphite oxidation used. The analysis in this section will serve to satisfy that requirement.

Consider a differential volume in space, $d V=d x d y d z$, containing mostly graphite but also a large number of small voids which are filled with helium carrier gas and steam impurity in the helium. The volumetric fraction of these voids is denoted by $\varepsilon$. A mass balance for steam molecules can be written for the elemental volume by considering 4 terms:

$$
\begin{gathered}
\text { net rate of leakage in - reaction rate + generation rate }= \\
\text { rate of change }
\end{gathered}
$$

The first term in the above expression results from gaseous diffusion through the pores of the graphite. The binary diffusion coefficient of steam in helium is given by

$$
\mathrm{D}=\frac{\mathrm{KT}^{\mathrm{n}}}{\mathrm{p}}
$$

where $\mathrm{T}$ is the absolute temperature, $\mathrm{p}$ is the total pressure, and $\mathrm{K}$ and $\mathrm{n}$ are constants. When steam diffuses through helium filled pores in graphite, the binary diffusion is inhibited and a normalizing factor is applied. Thus, an effective diffusion coefficient is defined as

$$
Z=\alpha D=\frac{\alpha K T}{p}
$$

The effective diffusion coefficient, when used together with the steam concentration in the free gas (i.e. undiluted by graphite molecules) yields the flux of steam through the graphite. If $c$ represents the undiluted steam concentra- 
tion then the net rate of steam leakage into $d V$, assuming $Z$ is isotropic and spatially independent, is by Fick's law:

$$
z\left[\frac{\partial^{2} c}{\partial x^{2}}+\frac{\partial^{2} c}{\partial y^{2}}+\frac{\partial^{2} c}{\partial z^{2}}\right]
$$

The second term in the steam balance equation is the reaction rate. Since

$$
\mathrm{C}+\mathrm{H}_{2} \mathrm{O} \longrightarrow \mathrm{CO}+\mathrm{H}_{2}
$$

it is clear that for each steam molecule removed there is also one graphite molecule reacted. From empirical correlations, such as the Langmuir-Hinshelwood equation, the fraction of graphite reacting per unit time can be found as a function of temperature and steam concentration. This fractional reaction rate, $R_{S t}$, is then related to the steam reaction rate in volume $d V$ :

$$
R_{S t} \frac{\rho A}{M_{g}} d V=K_{f} \frac{p_{s t} \varepsilon A}{R T} d V
$$

where

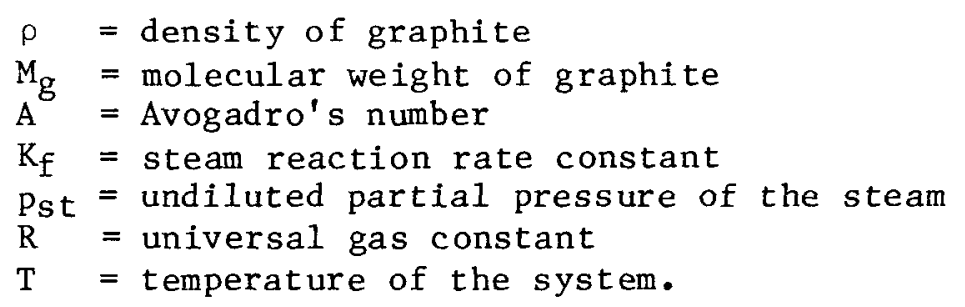

Equation (3-6) simply equates the reaction rate of steam molecules to the reaction rate of graphite atoms and yields $K_{f}$, the fractional reaction rate for steam:

$$
K_{f}=\frac{\rho R_{s t} R T}{p_{s t} M_{g} \varepsilon}
$$

Thus, the second term in the steam balance equation can be expressed as

$$
K_{f} c \varepsilon=\frac{\rho R_{s t} R T}{p_{s t} M_{g}} c=K_{v} c
$$

In order to evaluate $\mathrm{K}_{\mathrm{V}}$ numerically, one needs an appropriate expression for $\mathrm{R}_{\mathrm{st}}$. The Langmuir-Hinshelwood equation offers one such relationship:

$$
R_{S t}=\frac{k_{1} p_{s t}}{1+k_{2} p_{h}^{n}+k_{3} p_{s t}}
$$


where $\mathrm{ph}_{\mathrm{h}}$ is the partial pressure of hydrogen, $\mathrm{n}$ is an empirical constant and in which

$$
\mathrm{K}_{\mathrm{i}}=\mathrm{k}_{\mathrm{i}} \exp \left(-\mathrm{E}_{\mathrm{i}} / \mathrm{RT}\right)
$$

In Equation (3-10) $\mathrm{k}_{i}$ are the frequency factors and $E_{i}$ are the activation energies, all empirically determined.

The third term in the balance equation, the steam generation rate, $G$, is usually zero and is included explicitly for the sake of generality only.

The final term is also easily denoted. The rate of change of steam molecule concentration in volume $\mathrm{dV}$ (which is composed of graphite and steam-filled voids) is

$$
\frac{\partial(\varepsilon c)}{\partial t}=\varepsilon \frac{\partial c}{\partial t}
$$

Combining the 4 terms in the balance equation yields

$$
Z\left[\frac{\partial^{2} c}{\partial x^{2}}+\frac{\partial^{2} c}{\partial y^{2}}+\frac{\partial^{2} c}{\partial z^{2}}\right]-K_{v} c+G=\varepsilon \frac{\partial c}{\partial t}
$$

where $K_{V}$ is given by Equation (3-8).

To apply this to a test specimen in the graphite oxidation loop some simplifications are normally made. The cylindrical graphite test specimen is viewed as a semi-infinite, one-dimensional body with regard to steam corrosion at its surfaces. The mass transfer situation at the surface is also simplified for the sake of analysis; it is typically assumed that the concentration of steam at the graphite surface is the same as in the free helium stream outside the boundary layer. With these idealizations and under steady state conditions Equation $(3-12)$ becomes $(G=0)$

$$
\mathrm{Z} \frac{\mathrm{d}^{2} \mathrm{c}}{\mathrm{dx^{2 }}}-\mathrm{K}_{\mathrm{V}} \mathrm{c}=0
$$

with the boundary condition that $c=c_{0}$ at $x=0$. The solution of Equation (3-13) for a semi-infinite body is therefore

$$
c=c_{0} \exp \left[\begin{array}{ll}
-\sqrt{\mathrm{K}_{\mathrm{v}} / 2} & \mathrm{x}
\end{array}\right]
$$

where $\mathrm{x}$ is the distance from the surface into the body.

A design requirement for the loop is that the steam concentration should decrease by 5 percent as the helium passes over the graphite specimen. From Equation (3-14) the rate of steam entering the graphite surface (and thus lost 
to the helium stream) is

$$
m=-\left.z A_{S} \frac{d c}{d x}\right|_{x=0}=\sqrt{k_{v} Z} c_{0} A_{S}
$$

where $A_{S}$ is the surface area of the graphite. This amount of steam must thus be equal to 5 percent of the steam flow rate. If $Q$ is the helium volumetric flow rate, then

$$
\sqrt{\mathrm{K}_{\mathrm{v}} Z} \mathrm{c}_{\mathrm{O}} \mathrm{A}_{\mathrm{S}}=.05 \mathrm{c}_{\mathrm{O}} \mathrm{Q}
$$

or

$$
\mathrm{Q}=20 \mathrm{~A}_{\mathrm{S}} \sqrt{\mathrm{K}_{\mathrm{V}} \mathrm{Z}}
$$

The numerical evaluation of the flow rate requires values for temperature, pressure, steam concentration and a host of other HTGR operating conditions which altogether determine $\mathrm{K}_{\mathrm{v}}$ and $\mathrm{Z}$. The necessary parameters have been calculated for a nominal set of operating conditions using the OXIDE-3 code and the resulting values of $\mathrm{K}_{\mathrm{v}}$ and $\mathrm{Z}$ for the experimental conditions anticipated are $2.12 \times 10^{7} 1 / \mathrm{hr}$ and $6.19 \times 10^{-3} \mathrm{ft}^{2} / \mathrm{hr}$, respectively. 4 The helium flow rate in the test section according to Equation (3-16) is then $55,300 \mathrm{ft}^{3} / \mathrm{hr}$ for a graphite specimen 30 inches long with a 10 inch diameter. This result is, of course, at the test section conditions; viz. $1800 \mathrm{~F}$ and 735 psia. Flow rates at other conditions, such as at the circulating pump inlet, follow from application of the gas laws.

\subsection{Heat Transfer and Fluid Dynamics Considerations}

The necessary degree of sophistication of the thermal and hydraulic analysis for purposes of this preliminary design is rather limited. All that is needed for the present purpose are computations of heat transfer surface areas in the recuperators and dump heat exchanger and an estimate of circuit pressure losses. Dittus-Boelter and Darcy-Weisbach constitutive relationships were used throughout. Some of the more important size determinations are outlined here.

\subsubsection{Recuperator Size}

The heat transfer coefficient on the tube side of the recuperator depends on the physical properties of the helium, the tube diameter and on the helium velocity according to

$$
\frac{\mathrm{hD}}{\mathrm{k}}=.023\left(\frac{\rho \mathrm{VD}}{\mu}\right)^{.8}\left(\frac{\mathrm{C}_{\mathrm{p}} \mu}{\mathrm{k}}\right)^{.4}
$$

The tube size chosen was $1 / 2$ inch and the helium velocity was 100 feet/second. With these assumptions the computed heat transfer coefficient on the tube side is $168 \mathrm{Btu} / \mathrm{hr}-\mathrm{ft}^{2} \mathrm{~F}$. The heat transfer coefficient on the shell side may be 
computed using a correlation similar to Equation (3-17) but is subject to more uncertainty. It was assumed for this study that the heat transfer coefficient on the shell side could be made to be about the same as on the tube side; therefore, neglecting the tube wall resistance the overall coefficient is about 80 $\mathrm{Btu} / \mathrm{hr}-\mathrm{ft}^{2} \mathrm{~F}$.

The total recuperator surface area is determined by the heat transfer coefficient, the duty and the average temperature difference between the hot and cool streams. The duty is fixed by the helium flow rate, established in Section 3.1 , and the temperature drop through the recuperator, $750 \mathrm{~F}$. The total duty is about 6 million Btu per hour and so with a temperature difference between tube and shell sides of $50 \mathrm{~F}$, approximately 1500 square feet of surface are required. With $1 / 2$ inch tubes the total tube length turns out to be 11,600 feet. In order to accommodate the helium flow rate at 100 feet/second, it is necessary to provide $1701 / 2$ inch tubes. Thus, the total recuperator bundle length will be 68 feet.

\subsubsection{Air Cooler Size}

The sizing of the dump heat exchanger is determined in the same manner as was used for the recuperator. A reasonable tube diameter and helium flow velocity are chosen first and the other parameters are then determined directly. The main difference is that the air side heat transfer coefficient will be the limiting variable in determining the required surface area. Even with fins on the air side of the cooler it is doubtful that an overall coefficient of more than about $15 \mathrm{Btu} / \mathrm{hr}-\mathrm{ft} \mathrm{t}^{2} \mathrm{~F}$ can be achieved without going to undue expense and inconvenience. Typical values in furnace convection sections are around 10 $\mathrm{Btu} / \mathrm{hr}-\mathrm{ft} \mathrm{t}^{2} \mathrm{~F}$, as a point of comparison. The air side coefficient of the dump heat exchangers for the Fast Flux Test Facility (FFTF), as another example, is also about $15 \mathrm{Btu} / \mathrm{hr}-\mathrm{ft}^{2} \mathrm{~F}$. Since the mean temperature difference between helium and air (if an 80 per cent factor is applied) will be about $470 \mathrm{~F}$ (air enters at $70 \mathrm{~F}$ and exits at $800 \mathrm{~F}$, flowing countercurrent to the helium) the computed surface area, for a duty of $400,000 \mathrm{Btu} / \mathrm{hr}$, turns out to be around 57 $\mathrm{ft}^{2}$.

Now, choosing a tube diameter of $11 / 4$ inches and a helium velocity of 50 feet/second, the number of tubes required will be 21 . The necessary heat transfer surface requirements of 57 square feet is satisfied by a bundle of 21 tubes that is 8 feet long.

\subsubsection{Pressure Losses}

Until a final design, with all of the valves, elbows, elevation changes, pipe sizes, etc. is completed, the exact pressure losses cannot be determined. Fortunately, this much detail is not needed, since a reasonable estimate can be obtained from an overall knowledge of tube lengths and diameters, general layout, and equipment sizes.

Basically, a good guess for the total equivalent length of $1 / 2$ inch tubing the helium will travel in a pass through the circuit is the only requirement for 
the pressure drop calculation and this has been estimated to be about 200 feet. For the stipulated helium velocity of $100 \mathrm{feet} / \mathrm{second}$ the pressure drop is computed as about $12 \mathrm{psi}$. This is only half of what the circulator is designed to supply, leaving a comfortable margin that could be used up in more detailed designs of the loop in which sizes may be altered.

The pressure drop on the air side of the dump heat exchanger depends on the length and diameter of the air side and the velocity and properties of the air. For industrial processes an air velocity of $50 \mathrm{feet} / \mathrm{second}$ is commonplace. To remove $400,000 \mathrm{Btu} /$ hour from the helium with the $730 \mathrm{~F}$ air temperature rise stipulated, about 2200 pounds of air per hour are required. This leads to a cross sectional area of about $3 / 4$ foot at 50 feet/second in the air cooler. Thus, having determined the length ( $8 \mathrm{feet}$ ), the diameter (.75 foot) and the velocity (50 feet/second), frictional air pressure drop is computed to be about $.03 \mathrm{psi}$. Allowing for head losses in inlet and outlet ducts, the air fan would be required to produce a maximum of 5 inches $\mathrm{H}_{2} \mathrm{O}$ head. This is a standard requirement in engineering practice offering no unusual considerations.

\section{LOOP OPERATION}

The completed loop is intended to run at steady conditions for extended periods with minimal operator interaction. As with the Materials Test Loop at BNL, data will be taken and recorded automatically and the impurities will be controlled by the instrumentation and valving. The operator will periodically replenish consummable materials and make fine adjustments to the controlled parameters as needed.

\subsection{Startup and Shutdown}

In addition to initial shakedown procedures, all components will be individually tested in accordance with all applicable codes and standards, i.e., a pneumatic and a mass spectrometer leak test to ensure structural soundness and leak tightness. Wherever possible 100 percent radiography and die checks will be a part of the quality assurance program. After completion of the loop assembly, it will also be checked as a unit both pneumatically and with a mass spectrometer. Initial shakedown procedures should include motor startup, circulator operation and electric heater operation. Loop startup will consist of an initial helium purge, followed by a loop dump and evacuation. The loop will then be charged with helium to a pressure of about $250 \mathrm{psi}$. The circulator should be started and then the heater and cooler activated. After the required test section temperature is reached, the excess pressure would be vented. At this point the test run will commence.

After completion of the graphite exposure the electric heater will be deactivated. When the helium temperature is reduced close to ambient the air cooler would be tripped. Finally, the helium circulator would be shut down and the loop totally vented. The test section could then be opened for removal of the graphite test specimen. 


\subsection{Off-Norma1 Conditions}

The test loop will have the standard safety features common to all high pressure circulating loops, such as pressure relief valves, temperature limiters, etc. (see Section 2.9). Because the system contains a relatively large quantity of high pressure gas and since the test section and economizer operate near the material yield point, the entire assembly will be housed in a separate facility with suitable energy absorbing materials around the critical components. Access to these areas will be limited during operation by procedural rules and physical as well as administrative barriers.

Accident analyses for the system must await the final design and are not considered here in a quantitative manner. However, two scenarios are worth mentioning in general terms in this preliminary design study since these two are likely to be the limiting accidents for the loop.

\subsubsection{Loss of Helium F1ow}

In the event of a power outage or a circulator trip due to a number of other initiating events the circulator will coast down according to its characteristic curve. The logic of the safety circuits will be such as to deactivate the electric heaters which make up the final $50 \mathrm{~F}$ helium temperature rise. Depending on the circulator's coastdown characteristics the test section pressure boundary may become overheated. This will depend on the effectiveness of the convective heat removal compared to the radiant and conductive heat transfer to the outer walls of the test section and should be studied in detail once the circulatormotor characteristics and the detailed design of the test section are known. The heating of the pressure boundary much above its design temperature can bring the stresses in the test section (and economizer) to the yield point. A number of engineered safety features are possible, such as auxiliary power supplies, independent compressed helium systems, dump heat exchangers, etc. The simplest and least expensive, as well as reliable device, is to allow the system to blow down to some lower and safe system pressure. A fail safe valve actuator, that responds to a loss of helium flow and initiates a controlled depressurization of the loop, is recommended to mitigate the effects of such an event.

\subsubsection{Rapid Depressurization}

In contrast to a controlled depressurization as might be fostered in the event of a loss of helium flow, the rapid depressurization of the loop due to a mechanical failure of a section of the pressure boundary must be addressed. This type of "blowdown" problem involving heat transfer considerations, the dynamics of compressible fluids in a mechanically complex system, and the characteristics of rotating fluid machines coupled to an electrically driven induction motor can be solved by utilizing digital computer codes developed to study the dynamics of gas cooled reactor plants. Typical codes of this nature are the TAP $^{5}$ program developed by General Atomic Company, the HETCAT 6 program deve1oped at Kernforshungsanalage (KFA) Julich, or the HELAP 7 program written at BNL. In order to use any of these codes a detailed design of the loop and its 
components is essential.

It is anticipated that a rapid depressurization accident will not result in serious safety problems. It is felt that such an event will present a danger only to expensive equipment. The component which appears particularly vulnerable is the circulator. Approximately a 50 atmosphere pressure difference could exist across the vanes of the impeller, depending on where a piping failure is postulated. Depending on the specific design of the circulator, this could do irreparable damage to the impeller.

\section{ALTERNATIVE DESIGNS}

While scoping studies on the nominal design were progressing, the practicability of obtaining thick walled sections of high temperature materials came under scrutiny. Aside from the feasibility of obtaining such materials, the excessive cost of the alloys, even if they were available, became apparent. 8 The idea of jacketed piping, test section, and recuperator shells was considered briefly, but the complications. in mechanical design that this would lead to were judged to be outside the scope of this study. However, two other alternate systems were addressed that would be fabricable with readily available materials and at the same time much less expensive to build. These alternative designs are described in this section.

\subsection{Low Pressure Loop}

The obvious way to alleviate the materials problem is to lower either the operating pressure or the operating temperature of the critical components. The kinetics of graphite oxidation are much more sensitive to temperature than to pressure and so a reduction in operating pressure would be the indicated choice. Another reason for this decision has to do with the circulator. The manufacturer has stated that little cost savings could be accrued by lowering the circulator temperature. A major fraction of the cost is dependent on the motor power (which depends on flow rate and pressure drop in the 1oop) and the operating pressure. Thus for reasons of preserving chemical kinetics as much as possible and at the same time effecting significant cost savings, the first alternative design considered was a low pressure version of the nominal design.

A pressure of 50 psia was selected arbitrarily for the low pressure alternative. The main difference in terms of chemical kinetics that this leads to is a change in the diffusion coefficient in the graphite (see Equation 3-3). In order to maintain a 5 percent change in water vapor concentration as the helium passes over the specimen, the volumetric flow rate must be $3535 \mathrm{cfm}$ rather than $922 \mathrm{cfm}$ as in the nominal case (see Equation 3-16). However, since the pressure is reduced, this larger volumetric flow rate corresponds to a lower mass flow rate. Thus the recuperator, air cooler, and electric heater duties are all reduced to about one quarter of that in the nominal case. The design velocity of the helium was increased (because of the lower density) to $300 \mathrm{feet} / \mathrm{second}$ but the heat transfer coefficients would not be as large as in the nominal design (see Equation 3-17). Thus although the duties are much lower, heat transfer considerations lead to heat exchangers that are not any smaller than those for 
the nominal design. However, the thickness of the pressure barrier will be decreased more than an order of magnitude and therefore be not only available commercially but significantly less expensive.

Similarly, the size of the motor, which is determined by the power requirement for the circulator, will not be decreased at all. In fact, since the volumetric flow rate is about four times as much in the low pressure alternative as in the nominal case, and since the pressure drop is only somewhat reduced (density is decreased by a factor of 15 but velocity is increased by a factor of about 3) the power requirement and motor size will increase. However, the casing for the motor-circulator assembly, which accounts for a major portion of the cost, will be reduced in thickness by a factor of 15 .

Table 5.1 summarizes some of the parameters in the nominal and low pressure loop designs for convenient comparison. Chapter 6 gives an estimate of the capital cost of both of these systems.

$\underline{\text { Table } 5.1}$

Comparison of System Parameters

\begin{tabular}{lcccc}
\multicolumn{1}{c}{ Variable } & Nominal & & Low Pressure & Chamber \\
\cline { 1 - 1 } Test Section Temperature ${ }^{\circ} \mathrm{F}$ & & & & \\
Test Section Pressure psia & 1800 & & 1800 & 1800 \\
Helium Flow Rate cfm & 735 & & 50 & 50 \\
Helium Density lb/ft & 922 & & 3535 & - \\
Helium Flow Rate $1 \mathrm{~b} / \mathrm{hr}$ & 121 & & .00825 & .00825 \\
Helium Velocity in Tubes ft/sec & 6690 & & 1750 & - \\
Heat Exchanger HTC Btu/hr ft ${ }^{\circ} \mathrm{F}$ & 100 & & 300 & - \\
Recuperator Duty Btu/hr & 80 & & 28 & - \\
Electric Heater Duty kw & $6.3 \times 10^{6}$ & & $1.6 \times 10^{6}$ & none \\
Main Loop Pressure Drop psi & 122 & & 32 & - \\
Pumping Power hp & 12 & & 7.4 & - \\
& 50 & & 115 & -
\end{tabular}

\subsection{Chamber Design}

As will be seen in the following sections, even when the design pressure of the circulating loop is reduced to near ambient levels the capital cost of recuperators, air cooler, piping, and circulator bring the total cost of the system to over a million dollars. One way to eliminate these expensive components is to sacrifice the concept of a loop design to simulate conditions in the primary circuit of an HTGR altogether. This compromise leads to a chamber design as depicted in Figure 5.1 .

This concept, which also operates at about 50 psia, utilizes a self-contained helium system (except for a side stream for analysis, impurity removal and water 
addition) that is circulated over the graphite sample by a fan attached to a canned rotor. The rotor is protected from the $1800 \mathrm{~F}$ gas in the chamber by a radiant heat shield backed up by a water cooled screen. The fan shaft itself is cooled by water entering and leaving the shaft at the end opposite the fan. Helium leakage is minimized by the use of mechanical seals on both sides of the shaft bearings and by a labyrinth seal followed by an o-ring seal at the righthand side. Any remaining leakage could either be compressed and returned via the purification stream or alternatively, discarded. The shaft bearings themselves are floating gas bearings utilizing helium as the lubricant. Heat losses are made up by calrod heaters just downstream from the fan. The high temperature materials needed for the fan blades, etc. have been available and used in similar environments for decades. 9 Helium is ducted over the graphite sample by a sheath made of the same material as the fan blades.

\section{CAPITAL COST ESTIMATES}

The capital costs presented in this study are preliminary in nature and in the case of formed heavy walled sections of piping and vessels, somewhat speculative. This latter is due to the fact that high temperature alloys are not available in the required thicknesses at present. The costs shown do not include the cost of assembling the loop or the labor, engineering, administrative and overhead costs of operating and maintaining the system. The costs presented may be used for budgetary purposes to estimate the costs of finished components delivered to BNL.

\subsection{Nomina1 Design}

The capital cost estimates for the large scale graphite oxidation loop are summarized in Table 6.1. In estimating the cost of the test section, recuperator and piping, it was assumed that the material cost for Inconel 617 is about $\$ 10$ per pound and that the fabrication costs for these items are 25 percent, 40 percent and 50 percent of the material cost, respectively. The cost of the helium circulator, motor and power supply was obtained from the manufacturer directly. Electric heaters are made of an alloy of chrome, aluminum and iron that can operate at $2200 \mathrm{~F}$ and is readily available. The analytical section, the recording instruments and the control systems were estimated based on the experienced costs incurred for the Materials Test Loop and the Helium Impurities Loop at BNL. The cost of a mass spectrometer is not included in the tabulated figure because the HTGR Safety Division has already acquired such an instrument which could be adapted to the loop.

\subsection{Low Pressure Loop}

The cost estimates for the low pressure alternative are indicated in Table 6.1. Total material costs for the test section, recuperators and the piping were taken as one-third of those in the nominal design; the fabrication costs were assumed constant. The cost of the circulator and motor were obtained by assuming that half the cost of these components were due to material cost and these in turn were proportional to the operating pressure and to the power 
requirement raised to the exponent 0.28 . The overall sum of the costs for the low pressure loop is seen to be roughly $2 / 3$ that of the nominal design.

Table 6.1

Capital Cost Estimate for Three Designs $\left(10^{3} \$\right)$

\begin{tabular}{lrrrr} 
& Nominal & & Low Pressure & Chamber \\
\cline { 5 - 5 } Test Section & 100 & & 50 & 50 \\
Recuperators (4) & 400 & & 210 & - \\
Air Cooler & 10 & & 5 & - \\
Circulator and Motor & 550 & & 300 & 250 \\
Power Supply & 110 & & 140 & 100 \\
Engineering Design of Circulator & 130 & & 130 & - \\
Electric Heater & 10 & & 5 & 5 \\
Piping & 300 & & 170 & - \\
Valves & 25 & & 10 & 10 \\
Insulation & 40 & & 40 & 100 \\
Analytical, Recording, Control & 100 & & 100 & 15 \\
Structural Support & 25 & & 25 & 530 \\
TOTAL & 1800 & & 1185 &
\end{tabular}

\subsection{Chamber Design}

The parameter that has the greatest impact on capital costs for the chamber design is the pressure loss of the helium circulating over the graphite sample. The aerodynamics of the chamber design wil1, of course, determine the power requirements of the system and this has not been studied at all. The size of the motor and the necessary power supply greatly influence the costs of these items and they in turn constitute the major portion of the capital costs estimated in Table 6.1.

Acquisition of the propeller fan which offers no practical difficulty but the feasibility of assembling the wheel and driver into a workable unit has not yet been demonstrated. 10 Since some helium leakage is permissible, the mechanical design of this option is judged to be a viable alternative, provided that the achievable helium flow rates are satisfactory from the standpoint of graphite oxidation chemistry.

7. CONCLUSIONS AND RECOMMENDATIONS

A preliminary design study of a large scale graphite oxidation loop was done to assess feasibility and to scope capital costs. Two alternatives to the nominal case were considered as well.

The nominal design, which operates at $1800 \mathrm{~F}$ and 735 psia and accomodates a graphite specimen 10 inches in diameter by 30 inches long, is considered to be 
unfeasible at the present time due to the unavailability of thick sections of high temperature alloys. Even if these materials become available, the capital cost of equipment for such a facility would approach two million dollars.

A low pressure version of similar design could readily be built. The cost of a test loop operating at 50 psia would be about two-thirds that of the nominal design case. Finally, a test chamber design, which would also operate at 50 psia was investigated. By eliminating heat exchangers, circulator, and piping, a relatively inexpensive experimental facility for long term graphite exposures could be built at one-third the cost incurred for the nominal design. It is not obvious, however, that such a design would provide helium flow rates necessary for the experiments and this aspect would therefore require further study before proceeding with this concept.

In view of the unavailability of thick walled high temperature alloys, a design study of a system whose major components have cooled pressure boundaries is indicated. The mechanical design would be greatly complicated compared to the nominal design and thus a cost advantage is considered to be highly unlikely. The sole motivation for investigating such a concept is to provide a test section that simulates a truly prototypic HTGR environment and to accomplish this with materials currently available. 


\section{REFERENCES}

1. Letter from F. S. Ralbovsky (MTI) to L. G. Epe1 (BNL), Ref. MTI Proposal G9-567, Dec ember 15, 1978.

2. Telephone conversation between A. White (MTI) and L. G. Epe1 (BNL) on December $14,1978$.

3. M. B. Peroomian, A. W. Barsell and J. C. Saeger, OXIDE-3: A Computer Code for Analysis of HTGR Steam or Air Ingress Accidents, GA-A12493 (GA-LTR-7), January 1974.

4. J. Skalyo, Jr., L. G. Epel and C. Sastre, An Analysis of the Methods Utilized in OXIDE-3, BNL-NUREG-50810, Apri1 1978.

5. A. Bardia and R. C. Potter, TAP: A Program for Analysis of HTGR Nuclear Steam Supply System Performance Transients, GA-A13248 (GA-LTR-21), January 1976.

6. Personal communication from P. Quell (KFA) to L. G. Epel (BNL) during August 1975.

7. H. Ludewig and L. G. Epel, A Preliminary GCFR Plant Transient Analysis Using the System Code HELAP, BNL-FRS 74-1, September 1974.

8. Telephone conversation between D. Rahoi and D. Wenschoff (Huntington Alloy Product Division, International Nickel Co., Inc., Huntington, West Virginia) and S. Majeski (BNL) on April 6, 1979.

9. Letter from F. M. Fahrenwalt (Fahralloy Co.) to T. V. Sheehan (BNL), Ref: Fan Blades, March 29, 1979.

10. Letter from Bristal Metal Products, Inc. to T. V. Sheehan (BNL), Ref: High Temperature Fan, May 10, 1979. 


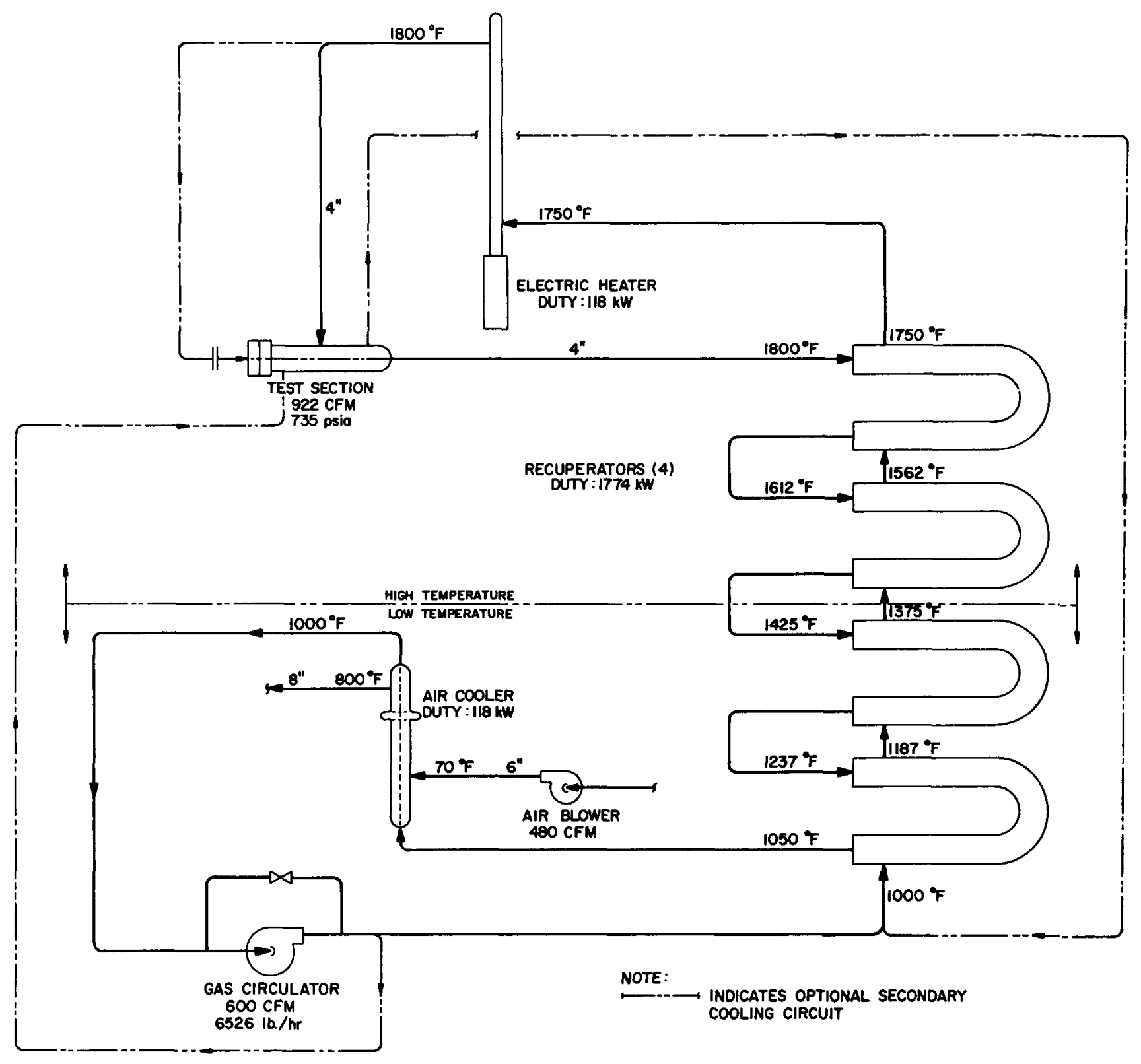

Figure 2.1. Process Flow Diagram - Nominal Design 


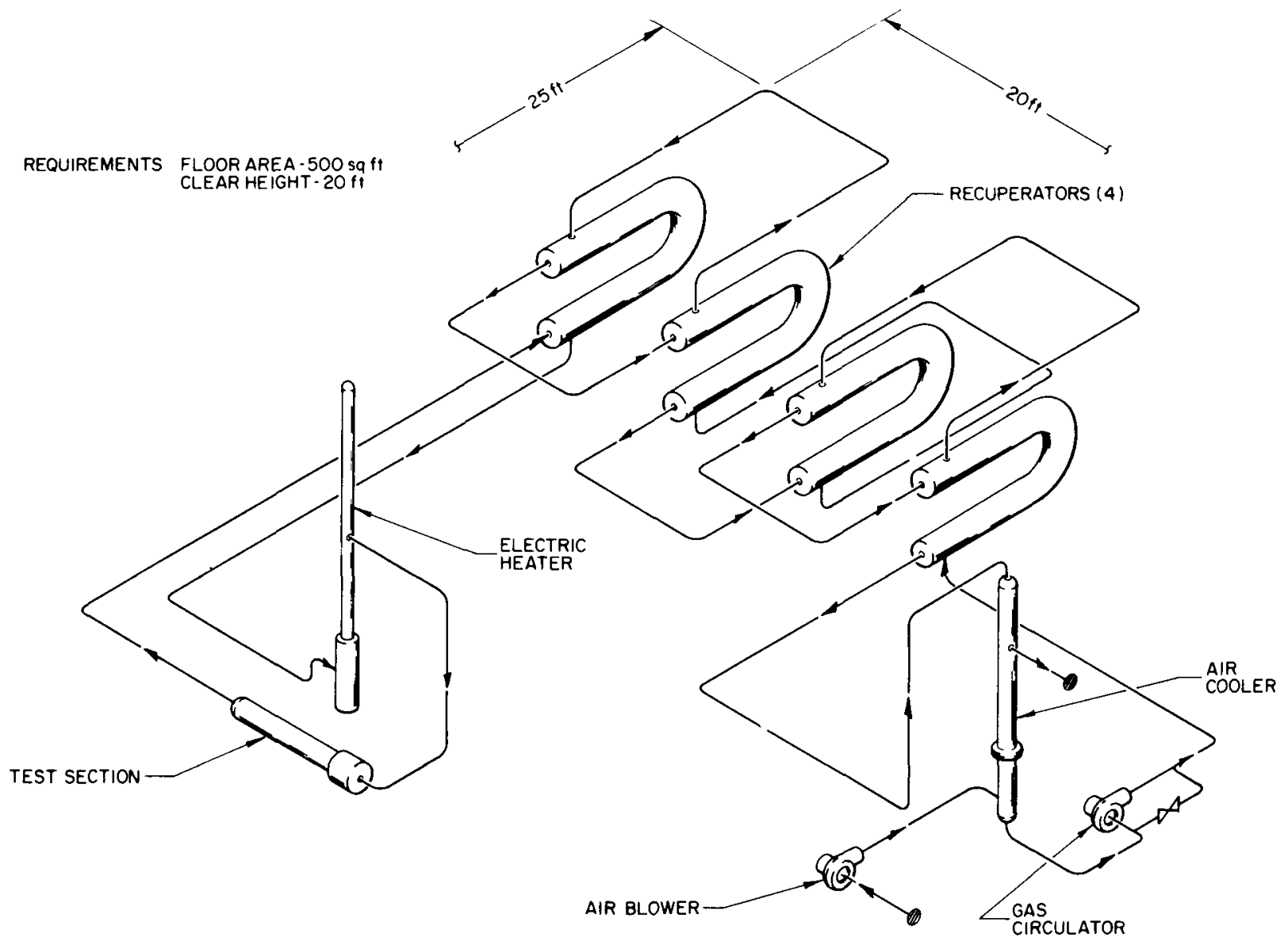

Figure 2.2. Preliminary Arrangement of Graphite Oxidation Loop 


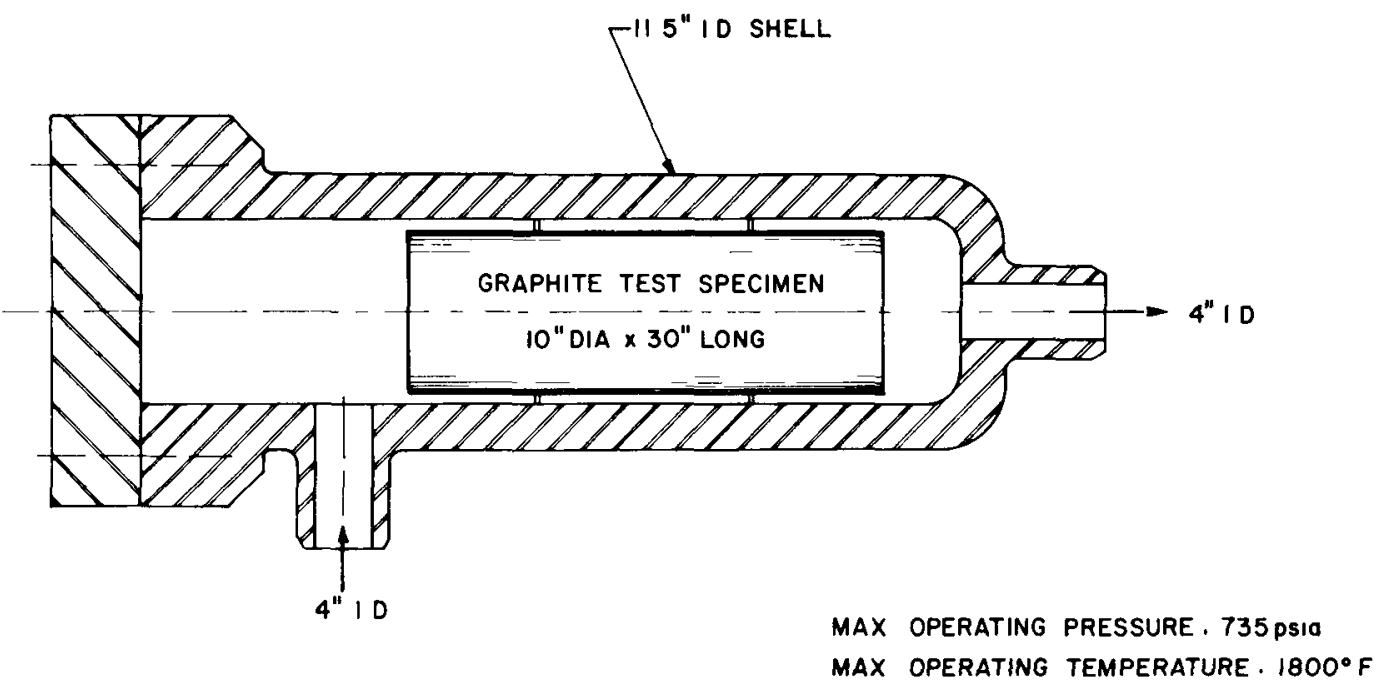

Figure 2.3. Test Section (Nominal Design)

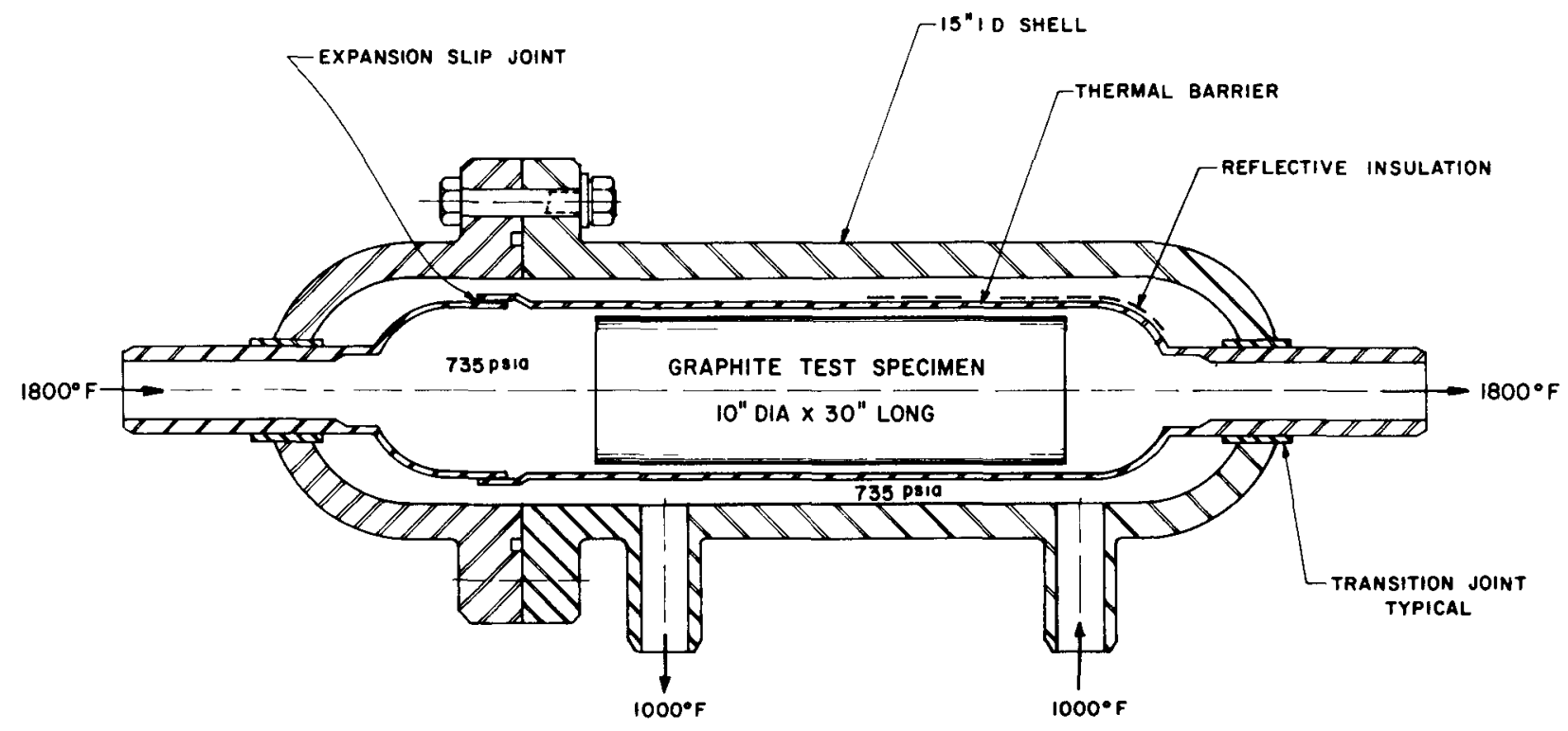

NOTE SLIGHT OP ACROSS THERMAL BARAIER SHELL REQUIRES LIGHT WALL

Figure 2.4. Test Section (With Thermal Barrier) 


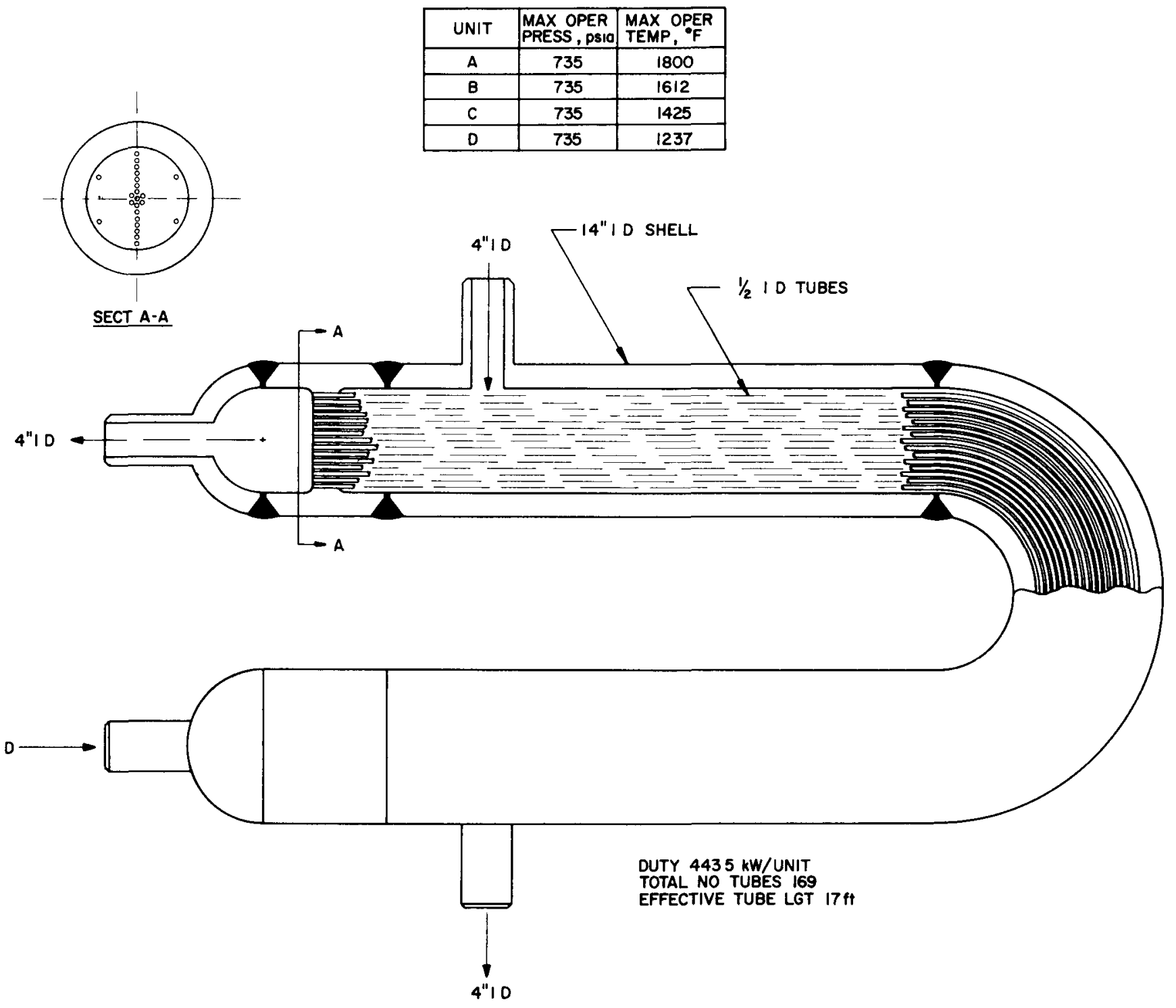

Figure 2.5. Recuperator 


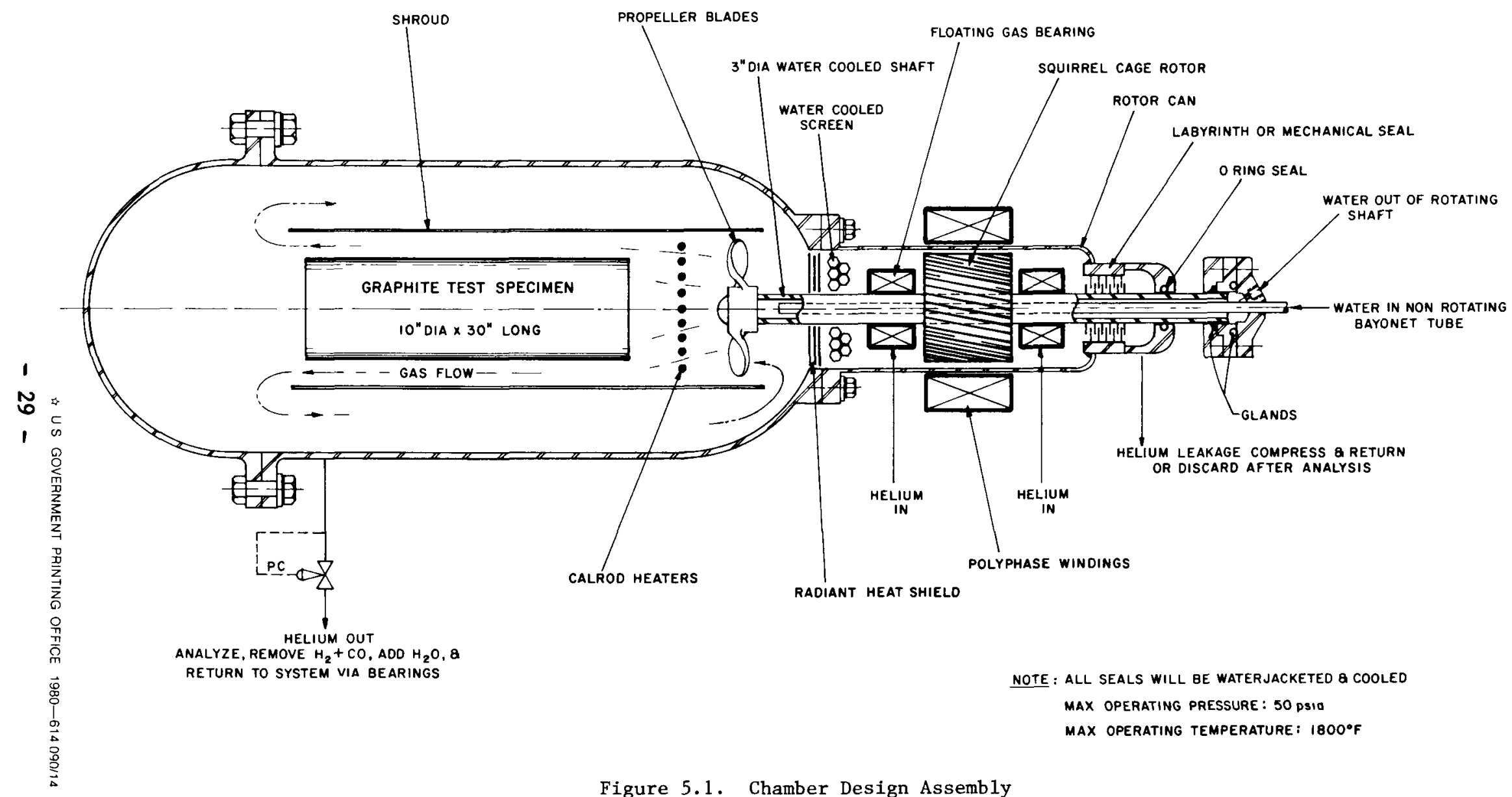

Figure 5.1. Chamber Design Assembly 